\title{
The association between tuberculin skin test result and active tuberculosis risk of college students in Beijing, China: a retrospective cohort study
}

Demin $\mathrm{CaO}^{1,2+}$, Zhiguo Zhang ${ }^{3 \dagger}$, Zhen Yang ${ }^{3}$, Shubo $\mathrm{Ma}^{3}$, Zhaogang Sun ${ }^{5}$, Huijuan Duan ${ }^{4}$, Baoli Zhu ${ }^{1,2^{*}}$ and Fei Zhao ${ }^{5^{*}}$

\begin{abstract}
Background: About 10\% latent tuberculosis infections (LTBI) would progress to active tuberculosis (TB), if left prophylactic therapy. Tuberculin skin test (TST) is the most widely used method for LTBI screening in the school of China. However, for college students, the association between TST reaction size and active TB risk was unclear.

Methods: We conducted a retrospective study to assess whether the TST reaction size would predict active TB during the next two years after TST screening for college students. Multivariable Cox regression was performed to identify the size of TST reaction and other factors associated with active TB risk.

Results: A total of 67292 college students in Beijing, China were included in this study; 8021 (11.92\%) individuals were TST positive $(\geq 10 \mathrm{~mm})$, and $3879(5.76 \%)$ of them were strong TST positive $(\geq 15 \mathrm{~mm})$. During the two years of follow-up, 26 active TB cases were reported in 134575 person-years with an incidence rate of 19.32 (95\% Cl: 12.6128.32) per 100000 person-years. The adjusted hazard ratios (HR) (95\% Cl) were 1.094 (0.247 4.846), 3.644 (1.188 11.179), 6.832 (2.436 19.163) and 9.768 (2.203 43.315) of cohorts with the TST reaction size intervals 5 9, 10 14, 15 20 and $\geq$ $20 \mathrm{~mm}$, respectively, compared to cohort with interval 0 4 mm. Besides, the adjusted HR (95\% Cl) was 3.593 (1.354 9.537) of males compared to females.

Conclusions: This study indicated that the risk of active TB increased in college students when the TST reaction size was $\geq 10 \mathrm{~mm}$, and males had a higher risk compared to females.
\end{abstract}

Keywords: Tuberculosis risk, Tuberculin skin test, College students

\section{Background}

Worldwide, it is estimated that one-third of the world's population is infected with Mycobacterium tuberculosis $(M t b)$. In 2017, about 10 million people suffered from tuberculosis, and $12-14 \%$ of them died. Wherein China has the second largest number of TB patients (best estimate, 88.9 million; range, 76.1 10.30 million) in the world [1]. About $5-10 \%$ of people with LTBI would suffer from active

\footnotetext{
* Correspondence: zhubaoli@im.ac.cn; zhaofei4814@bjhmoh.cn ${ }^{\dagger}$ Demin Cao and Zhiguo Zhang contributed equally to this work. ${ }^{1}$ CAS Key Laboratory of Pathogenic Microbiology and Immunology, Institute of Microbiology, Chinese Academy of Sciences, Beijing 100101, China ${ }^{5}$ Clinical Trials and Research Center, National Center for Geriatrics of Beijing Hospital, Beijing 100730, China

Full list of author information is available at the end of the article
}

TB. But approximately $60-90 \%$ such activation of TB would be prevented by early diagnosis and preventing treatment $[2,3]$.

School is a people-intensive place, in which students have been in prolonged face to face contact with each other. It is one of the most common places that reported for the community-based outbreak of TB in China $[4,5]$. It is significant to implement early diagnosis and prophylactic therapy in the prevention of school tuberculosis. At present, tuberculin skin test, based on purified protein derivative (PPD) induced delayed-type hypersensitivity, is still the main means in $M t b$ infection screening in China, because of its handleability and inexpensive price.

(c) The Author(s). 2019 Open Access This article is distributed under the terms of the Creative Commons Attribution 4.0 International License (http://creativecommons.org/licenses/by/4.0/), which permits unrestricted use, distribution, and reproduction in any medium, provided you give appropriate credit to the original author(s) and the source, provide a link to the Creative Commons license, and indicate if changes were made. The Creative Commons Public Domain Dedication waiver (http://creativecommons.org/publicdomain/zero/1.0/) applies to the data made available in this article, unless otherwise stated. 
Several studies have been performed among primary school students to estimate the risk of TB disease according to TST reaction size $[6,7]$. However, very few studies focused on the association of TST reaction size and TB risk among college students, who were during or pastpuberty with great changes of physiology and behavior. It was reported that the incidence of LTBI, as well as TB, for the people beyond the age of 15 years is higher than for them under that age $[6,8]$. In this study, we aim to investigate the relationship between the risk of active TB and the intensity of the TST response of college students.

\section{Methods}

\section{Study design and participants}

We performed a retrospective cohort study of the college freshmen TB infection investigation of 20 colleges, located in Changping district, Beijing, China. The baseline examination took place in 2013-2016. Follow-up for all individuals started at the time they received TST, mainly in mid-September each year. We ended followup for each individual with 2 years follow-up. The data were excluded if any of the following conditions exist: active TB diagnosis in freshmen TB screening, having active TB history or missing TST results.

\section{Data collection and procedures}

Beijing Changping institute for tuberculosis prevention and treatment (BCITPT) is the public health institution mainly responsible for $\mathrm{TB}$ prevention and control in Changping district. Raw records of colleges' freshmen TB screening of 2013-2016, which contained the age, sex, ethnicity, region, TST reaction size, and diagnosis result, were obtained from BCITPT. Data on reported TB cases of the colleges in Changping district were retrieved from national TB reporting system from 2013 to 2018. Besides, the incidence time of each TB case was collected for further analyses.

According to the medical records of BCITPT, TST was conducted with 2 units of tuberculin (TB-PPD, Beijing Sanroad biological products co., Ltd) on the left forearm using the intradermal technique for each college freshman. And results were measured and recorded after $72 \mathrm{~h}$ of TST. For students with the strong positive reaction of TST (induration size $\geq 15 \mathrm{~mm}$ or the presence of blister or necrosis), the subsequent medical diagnosis was performed using X-ray, $M t b$ culture of sputum and microscopy examination of sputum smears and so on. The individuals with TST reaction size $\geq 20 \mathrm{~mm}$ (886 ones in this study) were advised to receive preventive therapy. However, it was non-obligatory, a few students received preventive therapy, and because it needs three months of treatment, few ones successfully complete treatment. In this study, no one was excluded from the analysis due to receiving LTBI treatment. In the follow-up years, the student who was suspected to be TB case would be taken to BCITPT by the head teachers of classes of colleges in the first time, and all the suspected active TB cases in Changping district were confirmed and treated in BCITPT. They all accepted X-ray examination, microscopy examination of sputum smears and $M t b$ culture of sputum. The diagnosis and classification of TB were based on the national guidelines for diagnosis for pulmonary tuberculosis (WS 288-2008) and Classification of tuberculosis (WS 196-2001) [9, 10].

\section{Statistical analyses}

All analyses were performed using $\mathrm{R} 3.5 .2$ in this study. Pearson's Chi-square test or Fisher' exact test, where appropriate, was used to compare the frequency of categorical variables between the cohorts. The incidence rate (IR) and 95\% confidence interval (CI) for each cohort were calculated. A 2-tailed $P$ value of less than 0.05 was used to identify the statistical significance for all tests. Separately, cumulative incidence curves for different categories of sex and TST reaction size levels were plotted by using the Kaplan-Meier method, and the log-rank test was used to compare the curves. Subsequently, to identify the potential factors related to $\mathrm{TB}$ incidence, regression analysis based on Cox's proportional hazards model was applied to estimate the unadjusted and adjusted hazard ratio (HR) and $95 \% \mathrm{CI}$. The univariates with $P$ values less than 0.10 were then candidates included in multivariate Cox's regression analysis. Besides, HR analyses of subgroups of males and females were performed with the same methods. The absolute risk of active TB (1/100000) of different TST reaction sizes was calculated and plotted.

\section{Results}

As shown in Table 1, a total of 68288 individuals were included in the enrollment TB screening project of college students during 2013-2016, and 67428 of them actually participated. There were no significant differences in age, sex, and region between those who agreed to participate and those who didn't. After excluding 88 individuals diagnosed as active $\mathrm{TB}$ and 48 ones who had active TB history, 67292 (98.54\%) individuals were included in the final follow-up cohort. They came from 31 provincial divisions of China, including Beijing (16234, 24.12\%), Hebei (3922, 5.83\%), Shandong (3125, 4.64\%), He'nan (2889, 4.30\%), Xinjiang (2086, 3.10\%) and so on. There were 36351 (54.02\%) males and 30941 (45.98\%) females. And the mean (standard deviation, SD) age of the students was 19.52 (1.26) years at baseline (Additional file 1: Table S1).

There were 8021 (11.92\%) TST positive individuals (induration size $\geq 10 \mathrm{~mm}$ or the presence of blister or necrosis), and about half of them $(3879,5.76 \%)$ were strong TST positive (induration size $\geq 15 \mathrm{~mm}$ or presence of blister or necrosis) (Table 1). For TST negative individuals, 
Table 1 Baseline characteristics of students

\begin{tabular}{|c|c|c|c|c|c|c|c|}
\hline \multirow[t]{2}{*}{ Year } & \multirow{2}{*}{$\begin{array}{l}\text { Enrollment } \\
\text { of freshmen }\end{array}$} & \multirow{2}{*}{$\begin{array}{l}\text { \# of } \\
\text { follow-up }\end{array}$} & \multicolumn{2}{|l|}{ Sex } & \multirow{2}{*}{$\begin{array}{l}\text { Age (means } \\
\pm \text { SD) }\end{array}$} & \multirow{2}{*}{$\begin{array}{l}\text { TST } \\
\text { positive(\%) }\end{array}$} & \multirow{2}{*}{$\begin{array}{l}\text { Strong TST } \\
\text { positive(\% }\end{array}$} \\
\hline & & & Male(\%) & Female(\%) & & & \\
\hline 2013 & 14899 & 14592 & 45.59 & 54.41 & $19.78 \pm 1.53$ & 10.85 & 5.10 \\
\hline 2014 & 20081 & 19823 & 51.70 & 48.30 & $19.52 \pm 1.13$ & 10.60 & 4.61 \\
\hline 2015 & 18914 & 18659 & 58.63 & 41.37 & $19.37 \pm 0.95$ & 13.53 & 6.92 \\
\hline 2016 & 14394 & 14218 & 59.86 & 40.14 & $19.35 \pm 1.04$ & 12.74 & 6.54 \\
\hline Total & 68288 & 67292 & 54.02 & 45.98 & $19.52 \pm 1.26$ & 11.92 & 5.76 \\
\hline
\end{tabular}

TST positive: induration size $\geq 10 \mathrm{~mm}$ or the presence of blister or necrosis

Strong TST positive: induration size $\geq 15 \mathrm{~mm}$ or the presence of blister or necrosis

reaction sizes of them were mainly distributed in $0 \sim 1$ (51401, 76.39\%), 4 5 (5278, 7.84\%) and 8 9 (1328, 1.97\%); for TST positive individuals, the reaction sizes of them were mainly distributed in 10 11 (2849, 4.23\%), 12 13 $(1279,1.90 \%)$ and 14 15 (1925, 2.86\%) (Additional file 1: Table S2). There were significant differences between the students with TST positive and TST negative in sex, ethnicity, and region (Additional file 1: Table S3). Specifically, males had a higher percentage of TST positive compared to females $(12.18 \%$ vs. $11.61 \%)$; non-Han cohort had a higher percentage of TST positive compared to Han cohort ( $15.86 \%$ vs. $11.45 \%)$; the distribution trends of regions of TST positive was high in the west and low in the east (west: $14.22 \%$, middle: $12.39 \%$, east: $10.55 \%$ ).

There were 26 active TB cases during the 2 years of follow-up. Three of them were diagnosed by microscopy examination of sputum smears; three of them were diagnosed by $M t b$ culture of sputum, and the others were diagnosed due to TB-related symptoms. During the oneyear follow-up period, 9 cases of active TB were recorded in 67292 person-years with an incidence rate of 13.37 (95\% CI: 6.11 25.40) per 100000 person-years. And for two-year follow up, 26 active TB cases were recorded in 134575 person-years with an incidence rate of 19.32 (95\% CI: 12.61-28.32) per 100000 person-years. However, no significant difference in incidence rate was observed between the one-year and two-year follow up. Compared with the incidence rate of female (8.08 per 100000 person-years, 95\% CI: 2.62 18.86), male individuals $(28.89$ per 100000 person-years, $95 \%$ CI: 17.88 44.17) had a higher incidence rate $(P=0.01)$. The comparison among subgroups who came from different regions of China indicated that those from western China had the highest incidence rate, which might be due to the higher rate of LTBI in those regions at baseline. But no significant difference in the incidence rate was observed among students from different regions of China, as well as Han and non-Han ethnicity (Table 2). According to the Chi-squared test for trend in proportions, it was observed that the incidence rate showed an increasing trend with increasing of TST reaction size (chi-squared $=24.037, P<0.001$ ).
Factors that significantly related to active TB incidence were sex and TST response. As shown in Fig. 1, the cumulative incidence of active TB had a significant difference between males and females (Fig. 1a), as well as subgroups with different TST reaction size levels (Fig. 1b). The significant variables for the active TB were summarized in Table 2. After adjusted with other factors, the males were found to have a higher risk of $\mathrm{TB}$ development by comparing with the females, with an adjusted HR 3.359 (95\% CI: 1.354 9.537). For the TST response intensity, there was no significant difference of active TB risk between individuals with mean diameter of TST induration $0 \sim 4 \mathrm{~mm}$ and $5 \sim 9 \mathrm{~mm}$ (adjusted HR: 1.094, [95\% CI, 0.247 4.846], $P=0.91$ ). However, when the induration size was greater than $10 \mathrm{~mm}(10 \sim 14$, $15 \sim 19$ and $\geq 20$, respectively), the adjusted HR (95\% CI) showed an upward trend (3.644 [1.188 11.179], 6.832 [2.436 19.163] and 9.768 [2.203 43.315], respectively) (Table 2). From $0 \sim 4$ to $\geq 20$, the absolute risk of active TB $(1 / 100000)$ were $25.02,27.38,94.85,171.35$, and 225.73, respectively. As can be seen from Fig. 2, there was little difference in the absolute risk of active TB between TST reaction size $0 \sim 4 \mathrm{~mm}$ and $5 \sim 9 \mathrm{~mm}$, but it was increased rapidly with TST reaction size greater than $10 \mathrm{~mm}$. Moreover, subgroups analyses of males and females showed that HR of the cohort with TST reaction size $\geq 10 \mathrm{~mm}$ was 5.41 (95\% CI: $2.28 \sim 12.84, P<0.001$ ) compared to those with reaction size $<10 \mathrm{~mm}$ for males, and 5.08 (95\% CI: 0.85 30.37, $P>0.05$ ) for females. This suggested that in males, the risk of active TB was higher in college students with the TST positive results, but the difference was not significant for females.

\section{Discussion}

In this retrospective study, we found that TST reaction size $\geq 10 \mathrm{~mm}$ in college freshmen predicted an increased risk of active TB in the subsequent 2 years of TST, compared with those with a reaction size $<10 \mathrm{~mm}$. Specifically, the active TB risk increased about 3 times per $5 \mathrm{~mm}$ increasing of the interval of TST reaction size compared to reaction size $\leq 5 \mathrm{~mm}$, up to 9.768 times with reaction size $\geq 20 \mathrm{~mm}$. And the distribution of the absolute risk of active 
Table 2 Factors associated with active TB incidence in follow-up individuals

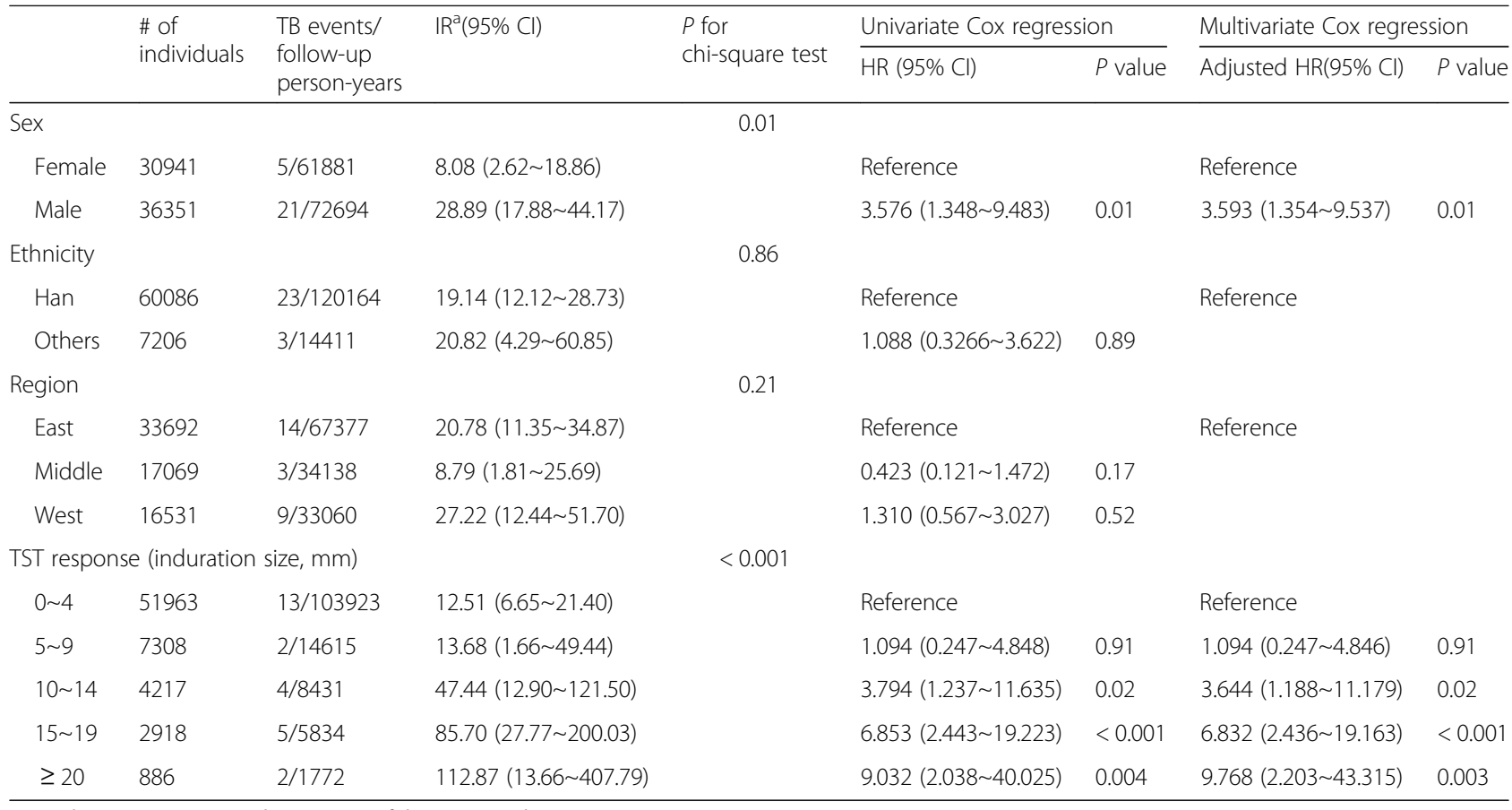

$I R$ Incidence rate, $H R$ Hazard ratio, $\mathrm{Cl}$ Confidence interval

${ }^{a}$ Per 100000 person years

TB of different induration sizes had similar features. Some previous studies also indicated that a person with a TST reaction size $\geq 15 \mathrm{~mm}$ had a high risk of active TB [6, 11]. However, college students, who were experiencing or going through puberty with great changes of physiology and behavior, were not included. Our study provided some evidence that strong TST reaction in the age of 17-21 years old could be used to predict the subsequent development of TB in two years after TST.

As the most effective and economical means for prevention from $M t b$ infection, vaccine coverage rate for bacillus Calmette-Gue'rin (BCG) has been around 97\% since 1999 in China [12]. However, prior BCG vaccination had a strong influence on TST results on account of crossreactivity among young people [13], which may lead to false positive results. Even though some more specificity and sensitivity methods have been developed, such as QuantiFERON-TB Gold, T-SPOT.TB and so forth [8, 14, $15]$, they have not yet been widely accepted in less developed areas because of their higher costs and complexity. Prophylactic therapy, with efficacy ranging from 60 to $90 \%$, was necessary for LTBI persons $[2,16,17]$, but not all TST positive ones. It was operable that the college students of TST reaction size $\geq 10 \mathrm{~mm}$, about $11.92 \%$ (8021/67292) of
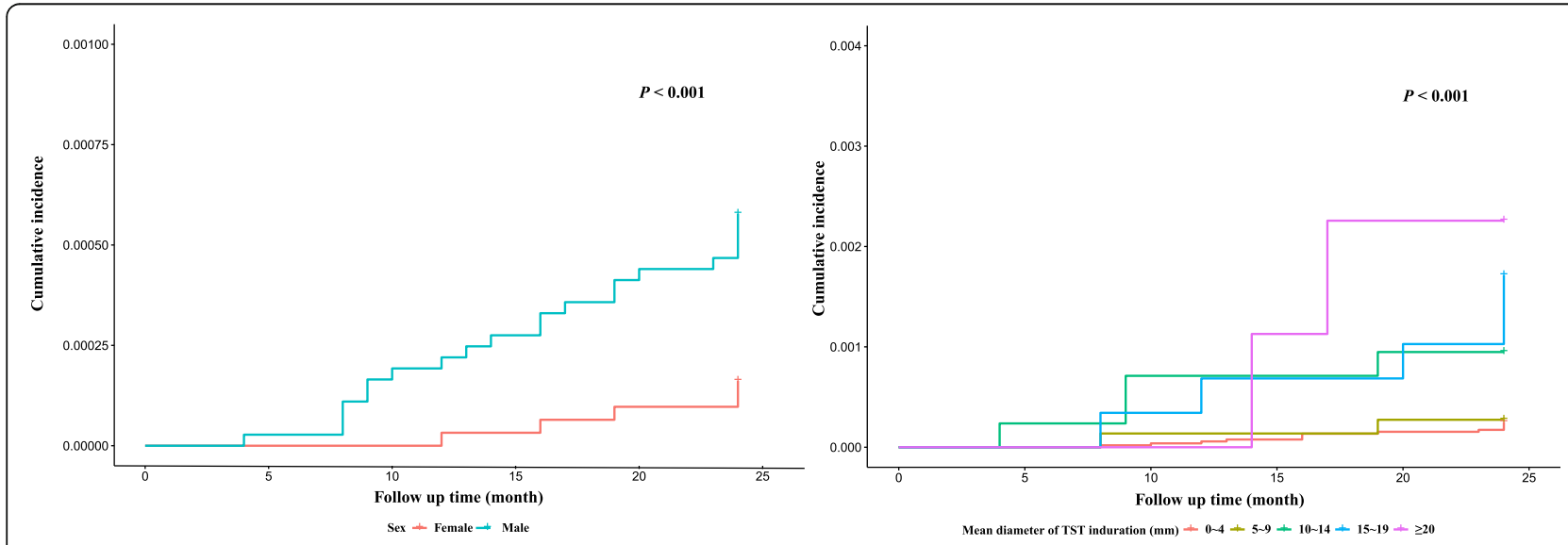

Fig. 1 Cumulative incidence curves of active TB estimated by Kaplan-Meier method. (a) Cumulative incidence curve analysis of different intervals of the mean diameter of TST induration (0 4, 5 9, 10 14, 15 19 and $\geq 20)$ (b) Cumulative incidence curve analysis of sex 


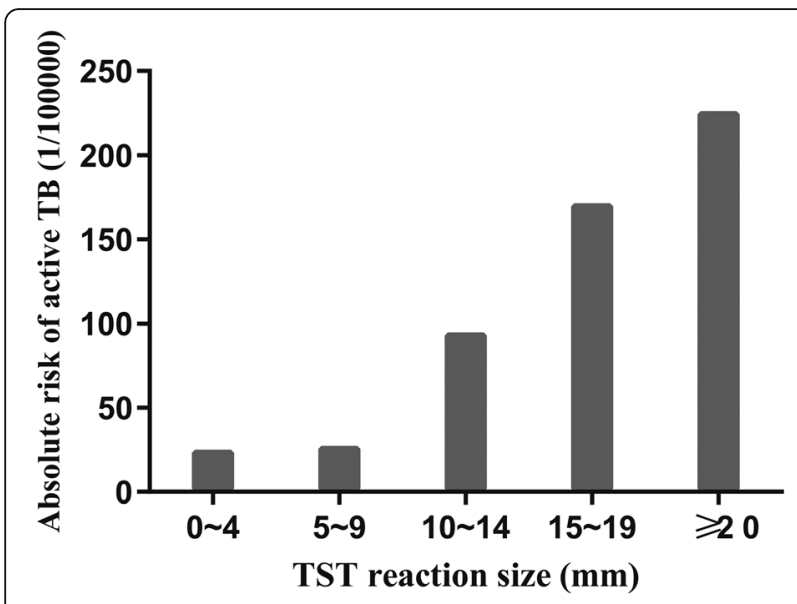

Fig. 2 The absolute risk of active TB of different TST reaction sizes

the whole, were regarded as a high-risk population and did further screening with QFT or T-SPOT.

Furthermore, the males of students predicted a higher risk of active TB compared to females, which was consistent with the results of previous studies [18-20]. Adolescence is a bifurcation point between males and females for the incidence of some infectious disease [21]. There are two reasons that may lead to the difference in active TB incidence. One is the physiological difference between them. Sex hormones play a significant role in immune responses; the female sex hormone estrogen tends to be immune-enhancing, while the male sex hormone testosterone is usually immune-suppressive [21, 22]. The other is the behavioral difference in male and female. $M t b$ is a person-to-person transmitted pathogen mainly according to the droplet, but behavior-related exposure is usually higher among males, especially after puberty [23]. Thus, the sex-bias of immune status and $M t b$ exposure may lead to the different risk levels of incidence of active TB.

There were a few limitations in this study. At first, the absence information of some other influencing factors, such as BMI, smoking and alcohol drinking history, close contact history, comorbidity and so forth, in the raw records might lead to ignoring some risk factors and influencing the accuracy of results. Secondly, because of the missing information of students received LTBI treatment, the risk of active TB for those with TST reaction size $\geq 20 \mathrm{~mm}$ might be underestimated in this study. Thirdly. follow up time was not long enough. It was reported that TB risk decreased rapidly with time after $M t b$ infection [15, 24]. Longtime follow-up might provide more information on the relationship of TST reaction intensity and active $\mathrm{TB}$ risk of this population. In addition, this study was only performed in Beijing. Therefore, additional research should be done in a wider area of China with longer follow-up time to estimate the association between TST result and active TB incidence in the youth population.

\section{Conclusions}

In summary, the intensity of TST reaction could reflect the active TB risk to some extent for college students. And males had a higher risk compared to females. This may allow us to do a better job in the prevention of pulmonary tuberculosis of college students in the future.

\section{Additional file}

Additional file 1: Table S1. The age distribution of the follow-up cohort. Table S2. The TST reaction size distribution of follow-up cohort. Table S3. The characteristics of individuals with TST positive and TST negative. (DOCX $21 \mathrm{~kb}$ )

\section{Abbreviations}

BCG: Bacillus Calmette-Gue'rin; BCITPT: Beijing Changping institute for tuberculosis prevention and treatment; $\mathrm{Cl}$ : Confidence interval; HR: Hazard ratio; IR: Incidence rate; LTBI: Latent tuberculosis infections; Mtb: Mycobacterium tuberculosis; PPD: Purified protein derivative; PR: Prevalence rate; SD: Standard deviation; TB: Tuberculosis; TST: Tuberculin skin test

Acknowledgements

Not applicable.

\section{Authors' contributions}

DMC and ZGZ contributed equally to this work. FZ, ZGZ, and BLZ conceived and designed this study. SBM, ZGS, HJD and ZY collected the data. DMC performed the analysis and wrote the manuscript. All authors read and approved the final paper.

\section{Funding}

This study was supported by the Strategic Priority Research Program of the Chinese Academy of Sciences (No. XDB29020203) and the National Science and Technology Major Project of China (No. 2018ZX10103001). The funders had no role in study design, data collection, analysis and interpretation.

\section{Availability of data and materials}

The datasets used and/or analyzed during the current study are available from the corresponding author on reasonable request.

Ethics approval and consent to participate

This work has been approved by the Ethics Committee of Beijing Changping institute for tuberculosis prevention and treatment. Existing TB Screening records and clinical data of college students were abstracted from the electronic medical records and anonymously used.

\section{Consent for publication}

Not applicable.

\section{Competing interests}

The authors declare that they have no competing interests.

\section{Author details}

${ }^{1}$ CAS Key Laboratory of Pathogenic Microbiology and Immunology, Institute of Microbiology, Chinese Academy of Sciences, Beijing 100101, China.

${ }^{2}$ University of Chinese Academy of Sciences, Beijing 100049, China. ${ }^{3}$ Beijing Changping institute for tuberculosis prevention and treatment, Beijing 102200, China. ${ }^{4}$ Beijing Tuberculosis and Thoracic Tumor Research Institute, Beijing 101149, China. ${ }^{5}$ Clinical Trials and Research Center, National Center for Geriatrics of Beijing Hospital, Beijing 100730, China.

Received: 23 April 2019 Accepted: 30 June 2019

Published online: 12 July 2019

\section{References}

1. WHO. Global tuberculosis report. Geneva: World Health Organization; 2018. 
2. WHO. Latent tuberculosis infection: updated and consolidated guidelines for programmatic management. Geneva: World Health Organization; 2018 .

3. Leung CC, Rieder HL, Lange C, Yew WW. Treatment of latent infection with Mycobacterium tuberculosis: update 2010. Eur Respir J. 2011;37(3):690-711.

4. Pan D, Lan R, Graviss EA, Lin D, Liang D, McNeil E, Lin M, Chongsuvivatwong V. Adolescent tuberculosis associated with tuberculosis exposure in classrooms and dorm rooms in Guangxi, China. Int J Infect Dis. 2019;78:8-14.

5. Huang Y, Zhong J, Wu Q, Liu Z, Pan A, Zhu L, Wang X. Investigation of a large school-based outbreak of tuberculosis infection in Eastern China. Pediatr Pol. 2016;91(6):541-6.

6. Leung CC, Yew WW, Au KF, Tam CM, Chang KC, Mak KY, Tam SY, Chan KF, Fong KL, Tam SW. A strong tuberculin reaction in primary school children predicts tuberculosis in adolescence. Pediatr Infect Dis J. 2012;31(2):150-3.

7. Leung CC, Yew WW, Chang KC, Tam CM, Chan CK, Law WS, Wong MY, Lee SN, Leung M. Risk of active tuberculosis among school children in Hong Kong. Arch Pediatr Adolesc Med. 2006;160(3):247-51.

8. Gao L, Lu W, Bai L, Wang X, Xu J, Catanzaro A, Cárdenas V, Li X, Yang Y, Du $J$, et al. Latent tuberculosis infection in rural China: baseline results of a population-based, multicentre, prospective cohort study. Lancet Infect Dis. 2015;15(3):310-9.

9. NHFPC. Diagnosis for pulmonary tuberculosis (WS 288-2008). In: National Health and Family Planning Commission of China; 2008.

10. NHFPC. Classification of tuberculosis (WS 196-2001). In: National Health and Family Planning Commission of China; 2001.

11. Chee CB, Soh CH, Boudville IC, Chor SS, Wang YT. Interpretation of the tuberculin skin test in Mycobacterium bovis BCG-vaccinated Singaporean schoolchildren. Am J Respir Crit Care Med. 2001;164(6):958-61.

12. NHFPC. National EPI vaccination and hepatitis $B$ vaccine coverage rate and the related factors: results from the 1999 Nationwide survey. Chin J Vaccines Immun. 2000;6(4):193-7.

13. Tissot F, Zanetti G, Francioli P, Zellweger JP, Zysset F. Influence of bacille Calmette-Guérin vaccination on size of tuberculin skin test reaction: to what size? Clin Infect Dis. 2005:40(2):211-7.

14. Pai M, Zwerling A, Menzies D. Systematic review: T-cell-based assays for the diagnosis of latent tuberculosis infection: an update. Ann Intern Med. 2008; 149(3):177-84

15. Lewinsohn DA, Lewinsohn DM, Leonard MK, Mazurek GH, LoBue PA Shinnick TM, Cohn DL, Daley CL, Desmond E, Keane J, et al. Official American Thoracic Society/Infectious Diseases Society of America/Centers for Disease Control and Prevention clinical practice guidelines: diagnosis of tuberculosis in adults and children. Clin Infect Dis. 2016;64(2):e1-e33.

16. Stagg HR, Zenner D, Harris RJ, Munoz L, Lipman MC, Abubakar I. Treatment of latent tuberculosis infection: a network meta-analysis. Ann Intern Med. 2014;161(6):419-28.

17. Chen $Q$, Wang XM, Qi Y, Liu XF, Jiang LP, Hou W, Zhou L, Lu XW. The impact of directly observed therapy on preventive treatment for latent tuberculosis infection among students in Dalian, China. Biomed Environ Sci. 2015;28(8):611-5.

18. Holmes CB, Hausler H, Nunn P. A review of sex differences in the epidemiology of tuberculosis. Int J Tuberc Lung Dis. 1998;2(2):96-104.

19. Neyrolles O, Quintana-Murci L. Sexual inequality in tuberculosis. PLoS Med. 2009:6(12):e1000199.

20. Gao L, Li X, Liu J, Wang X, Lu W, Bai L, Xin H, Zhang H, Li H, Zhang Z, et al. Incidence of active tuberculosis in individuals with latent tuberculosis infection in rural China: follow-up results of a population-based, multicentre, prospective cohort study. Lancet Infect Dis. 2017;17(10):1053-61.

21. Giefing-Kröll C, Berger P, Lepperdinger G, Grubeck-Loebenstein B. How sex and age affect immune responses, susceptibility to infections, and response to vaccination. Aging Cell. 2015;14(3):309-21.

22. Roved J, Westerdahl $H$, Hasselquist D. Sex differences in immune responses: hormonal effects, antagonistic selection, and evolutionary consequences. Horm Behav. 2017;88:95-105.

23. Guerra-Silveira F, Abad-Franch F. Sex bias in infectious disease epidemiology: patterns and processes. PLoS One. 2013;8(4):e62390.

24. Horsburgh CR. Priorities for the treatment of latent tuberculosis infection in the United States. N Engl J Med. 2004;350(20):2060-7.

\section{Publisher's Note}

Springer Nature remains neutral with regard to jurisdictional claims in published maps and institutional affiliations.

\section{Ready to submit your research? Choose BMC and benefit from:}

- fast, convenient online submission

- thorough peer review by experienced researchers in your field

- rapid publication on acceptance

- support for research data, including large and complex data types

- gold Open Access which fosters wider collaboration and increased citations

- maximum visibility for your research: over $100 \mathrm{M}$ website views per year

At $\mathrm{BMC}$, research is always in progress.

Learn more biomedcentral.com/submissions 